\title{
EXPLORATION ON GREEN COMMUNICATION TECHNOLOGIES FOR IOT IN HEALTH, EDUCATION AND INDUSTRY \\ ${ }^{1}$ P.Hemalatha M.E(Ph.D), ${ }^{2}$ Dr.K.Dhanalakshmi \\ ${ }^{1}$ Assistant Professor, ${ }^{2}$ Professor, ${ }^{1,2}$ Department of Computer Science and Engineering, ${ }^{1}$ IFET College of Engineering, ${ }^{2}$ PSNA College of Engineering and Technology 1hemadec4@gmail.com, ${ }^{2}$ dhanalakshmikrs@gmail.com
}

\begin{abstract}
To improve the protection of economyas well as environment, Green communication is used in Health, Education, Industry, as well as Ecosystem for overcoming the stumbling blocks which destroy the IoT's ecofriendly as well as sustainable nature of the sources of energy. Followed by that, to meet these problems, green communication technologies started to decrease the losses of energy as well as decrease electronic -wastes and contaminations; for example, energyaware tags, green cloud models, as well as resource-constrained data centers. Energyaware decreased RFID tags with least possible frequencies employed to efficientlytrackpatients, hospital bed allotments, automatically distributing the pills, managing attendances at the entrances in various institutes, tracking children at school, digital library cards, managing supply chains. Adding to that, the green cloud employs effective switching as well as
\end{abstract}

VM techniques to save energy, thereforeemployedto efficiently storeas well as retrieve of medical, institutional, as well as industrial data. Following that, green data centers alongside the least carbo footprints as well asconsuming power assistingMedical field, Educational, Industrial needsthrough saving the price for managing repositories. Though there are benefits, it is crucial to investigate it better using the new green computing technologies for IoT.This paper describesdifferent trade-offs whilemaking green IoTbe sustainable.It finds out an efficient platform to start new studies to demonstrate new and innovative green communication solutions for IoT in Health, Education, Industry.

\section{Introduction}

The rise of the Internet of Things (IoT) has potentially knowledge-sharing, commercial,and lifesaving capabilities within various domains since it equips a 
multitude of disciplines and millions of devices with connectivity. Recent decades have witnessed embodiments ofconnectivity forms that interlinks the stakeholders across the healthcare ecosystem to process the data. This assists to glean actionable insights to accomplish customer experience, care delivery, and operational excellence. Additionally, in educational institutions, a computational IoT nervous system encompasses resource tracking, lesson plan modeling, security empowerment, and ease of access to resources. Indeed, IoT has ushered in a new era for the industrial sector by adopting the revolution of the growing number of devices and sensors. Also, it provides a transformative data-driven approach that shifts the business lens from reactive, predictive, and preventive industrial operations. Although people automatically and collaboratively served by smart healthcare, education, and industrial innovations, the pervasive and ubiquitous nature of IoT generates a massive amount of data seamlessly exchanged across the network. Hence the energy-efficient communication technologies are required to foreseen sustainable IoT models with reduced energy consumption, enhanced energy-saving, and lessened impact of greenhouse gas emissions. This survey explores some of the prevailing green IoT communication techniques in health, education and industrial sectors.

\section{Smart IoT wearables for energy- aware health care applications- An extensive review}

IoT dependent smart health-care system applies remote at well asregular monitoring of various physiology signals such as electrocardiograms $\quad$ (ECG), electromyograms (EMG), electroencephalograms (EEG), BPof the peoplealong longer duration of time. IoTdependent WBAN couldcreate a considerable improvement in thethe health and wellbeing of people by identifying important health situations [1]. Designingsmallgadgets worn with combined WBAN needs less power nodes to sense, process as well as communicate the details [2]. Power management controller architecture for WBAN has been developed in IoT as anenergy-efficient solution in digital health. For monitoring thewellbeing of peoplealong long duration in WBAN, it is vital to distribute power as per the need as well aseffectively using the energy presentwhile the physiological signal is transmitted [3]. Devices with IoT has become strong as well as effective signal 
sharing paradigms from human body along numerous devices gadgets that are connected as shown in Fig. 1. The signal that are gatheredundergone process by processor on time and communicate them via WBAN. Most of the units arewith respectto functionality of a IoT activatedgadget for communicatingviageneral network are: power unit, processing unit, sensing unit as well as wireless communication unit [4]. They are connected by various communication interface for communicating within.
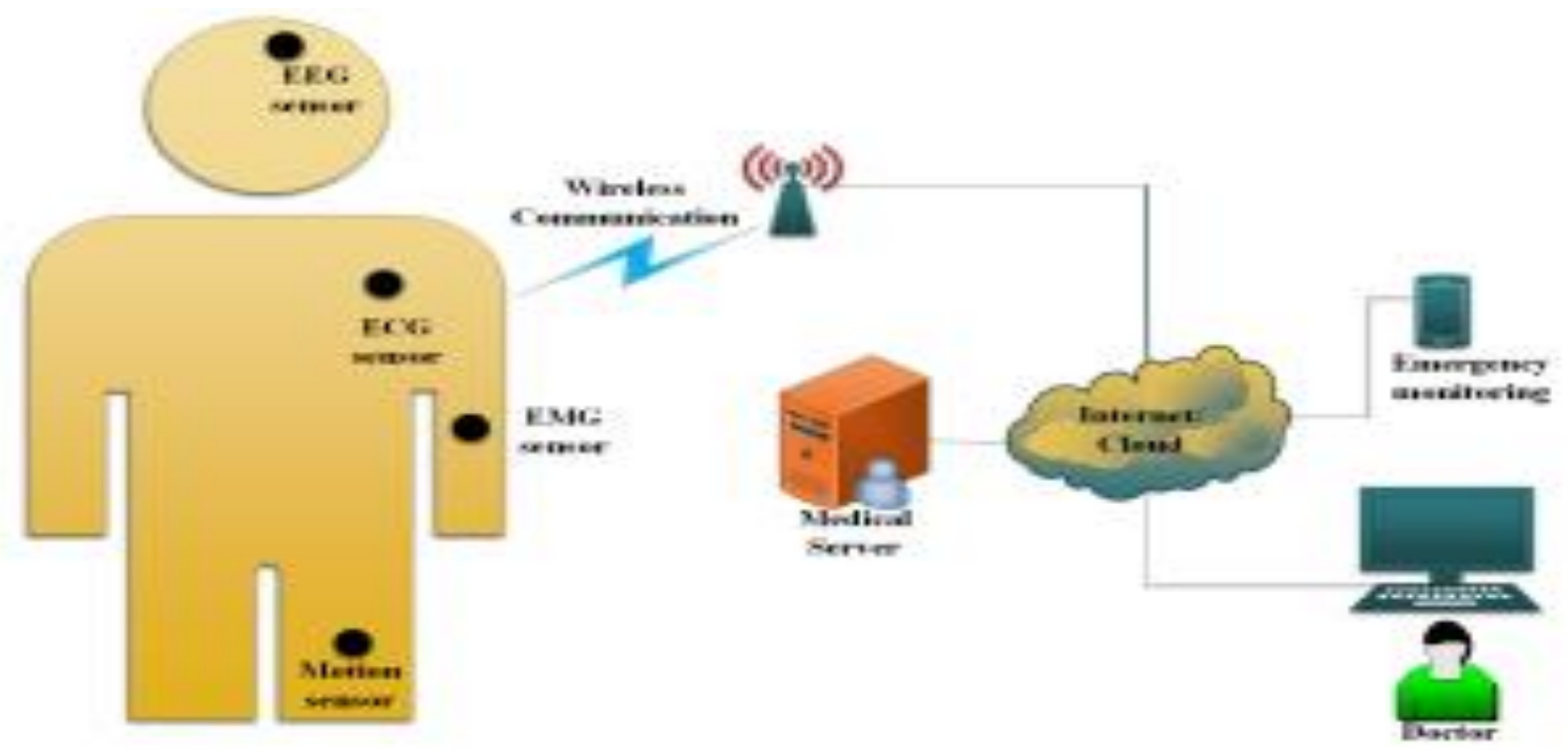

Figure 1. Smart IoT wearables

For enhancing the lifetime of IoT-driven WBAN, managing the power needs to be considered important while designing. Many IoT-usedgadgetsoperate on batteries that uses less power[5]. In the WBAN application, replacing battery is almost impossible. IoT-applied gadget in WBAN uses maximumpower to communicate sensor data to cloud server [6]. Usage of WBAN could be enhanced by cautiously managing the power consumption in various subsystem that are usedwhile communicating. Hence, cognitive power management controller is highly essential for improvingduration to which battery lasts for such network. Numerous strategies to save power were applied for IoTactivatedgadget in WBAN. Many are focusedto harvestpower from natural sources [7][8]. Still smart usage of power at 
handexists to be a demanding problem for general enhancement of the system power utilization. A System on Chip (SoC) dependentmanaging digital power controller was applied for biomedical application which uses power usingvarious threshold voltages. Till the power efficiency of $75 \%$ is obtainedusing power management unit. Energy utilization in WBAN to monitor ECG signalsthrough implementation of this in different duty cycle strategythrough varying load condition has been assessed in [9].

Even thoughthis demonstrates the lesser duty cycle as well aslight packet load improves the power efficiencyyet itscapability is decreased. An integrated Power Management Technique (PMT) supplied by batteries that cannot be charged is applied in [10] for applying with lower duty cycle. Alongside the 3 strategy that are power gating, leakage gating as well as power matching; a tradeoff among data latency as well as complexity is demonstrated. Through varying load as well as energy level of battery, yet an important partis to save power efficientlythrough this model.

\section{Approaches on energy-aware smart technologies IoT healthcare applications}

Copyright (C) Author
Energy efficiency depictsan important problem that impact the IoT services availability, reliability, and quality of service (QoS). The part gives a summary of the demonstrated ideas related to energy efficiency.

The author [11] proposed an energyefficient scheme that can beconsistent personal health monitoring. At first, theydepicted the needs of the process of regular monitoring of persons' wellbeing, by identifying a model resolution on every sensor. Following that, the authorsdemonstrated a CS-based (Compressive Sampling) scheme whichis composed of collecting data, transmitting it as well as storing mechanisms. The observationsdemonstrate the model's energy efficiency. Still, this does not consider the benefit of effective storage as well as processes in the Cloud.

In [12] the work, the authordemonstrated a cluster-based strategy for electronic medicalobservation. This scheme segregated the overall wireless sensor network to Clusters that includes cluster-head as well as body-head nodes to route the data among them. Above that, specific works con be given to cluster heads as well as to body heads, that considerablyincreases the 
effectiveness of overall monitoring system concerning to scalability as well as energy efficiency. The calculated observations demonstrate that the model energy efficient of the scheme along with improving the life of network. Still, the scheme concentratesto decrease the energy consumedat WSN part as well asavoids the Cloud part that considerably impacts energy consumption.

The author [13] demonstrated an IoT healthcare architecture depending on a smart gateway which utilizes the Power over Ethernet (PoE) standard. Considering thebenefit of the PoE cable, the smart gateway could cause efficient transmission of the data and supply IoT-activated gadget that has power. Also, the gateway couldlink to IoT medical sensors alongside the Cloud as well as process the collectedmedicalinformation, thatdecreases the loadon IoT sensors. The observations demonstrate that the gateway is an effectiveas well ascheapideas In medical department. Still, the gateway is effective during the use of wired sensors as well as fixed scenarios, hence we need to modify it to beappropriate to wireless sensors as well as unfixed situations.

In [14], the authorhas talked about the use of effective customization of 6LoWPAN
(IPV6 instead of less power WAN) in obtainingenergy saving as well as dependable IoTdependent e-Health applications. Using the designpeople's physiological data, like the electrocardiogram signals could be observed, analyzed as well as transmit in an effective techniquevia the customized 6LoWPAN. Especially, the architecture is made of the customized 6LoWPAN network whose intention isdealing with medical information, a gateway to routecreated packets of Things to a remote server on the Internet dependent on tunneling, as well as a WebSocket server to analyzemedical information in the Cloud. The study observationsdemonstrate the effectiveness of the demonstrateddesign related to the energy consumption, efficiencyas well as QoT for IoT-dependentmedical applications. Still, it needs more development for data filtering as well as compression in the IoT part for obtaining better energy efficiency.

Rault et al. [15] demonstrated energyefficient scheme to monitor patientwellbeing. The scheme concentrated on decrease the energy consumed at the sensors as well as the consumers' phone with the help of ZigBee as well as Bluetooth communications. Usually, the sensors, choose appropriate communication interface 
( either ZigBee or Bluetooth). If ZigBee interface is chosen, the Bluetooth interface is shut down on the mobile phone end, that conserves energy. At the same time, the mobile phonesoperate Bluetooth scanningon regular basis to identify sensors which needs to contactas there is no ZigBee correspondence. The simulation observationsdemonstrate that the scheme enhances the energy efficiency while avoiding any negative effects on its performance. Still, the scheme did not take into consideration the communication with the Cloud, that would warrant more solutions to obtainmore energy efficiency as well as performance.

In [16], a new framework using autoconfiguration for Cloud-based IoT platforms is employed. This framework gains advantageby integrating of system parameters, power consumption, adding to auto-configuration algorithms. The test observationsdemonstrate the effectiveness of the framework with respect tohow it performs as well as energy consumed. Still, the framework concentrates mainly on utilizing auto-configurations as well as other problemswhich affects energy consumption like the data transmission is not taken into consideration.
Li et al. [17] demonstrated a3-tier system architecture which is made of Things Tier, Fog Tier, as well as Cloud Tier. The Fog Tier is accountable fortakeprocess as well as storenearing to IoT edge thatdecreases the communication overhead. Usually, the architecture'sobjectiveis to reduce the transmission latency, as well as bandwidth overhead utilizing Fog as a middleware among the Cloud as well as IoT. The observation demonstrates the beneficial side of Fog to gain an effectiveCoT system architecture with respect to performance, communication latency, as well as energy consumption.

In [18], a service-basedTeleHealth architecture depending on Fog Data is proposed. The use of Fog Data makes the process of collection, storage and analysis ofclients' vitals easy. The Fog computer is accountable to analyze as well as filter - that is trimming unwanted raw data - the collected data earlier to transmission of the data to the Cloud that could cause considerable decrease inload of data which needs storage as well as deployed to the Cloud, while simultaneously improving the energy efficiency. The test observationsdemonstrate that the architecture didconsiderabledevelopments in consuming energy by decreasing the 
communication as well as the volume of detailsamong Fog and Cloud as well as improving the effectivenessof total medical and hospital system.

\section{Energy harvesting mechanisms for green sensing health care mechanisms}

Two class of energy harvesting architectures are depicted in Figures 2 and 3. Figure 4depicts the harvest-store-use energy architecture. The Figure 5depicts the harvest-use energy architecture.

If the energy is available around, it is harvested by this architecture energy and is stored forlaterutilization [19]. This is depicted in Figure 3, here a photovoltaic (PV) cell is taken as a model to

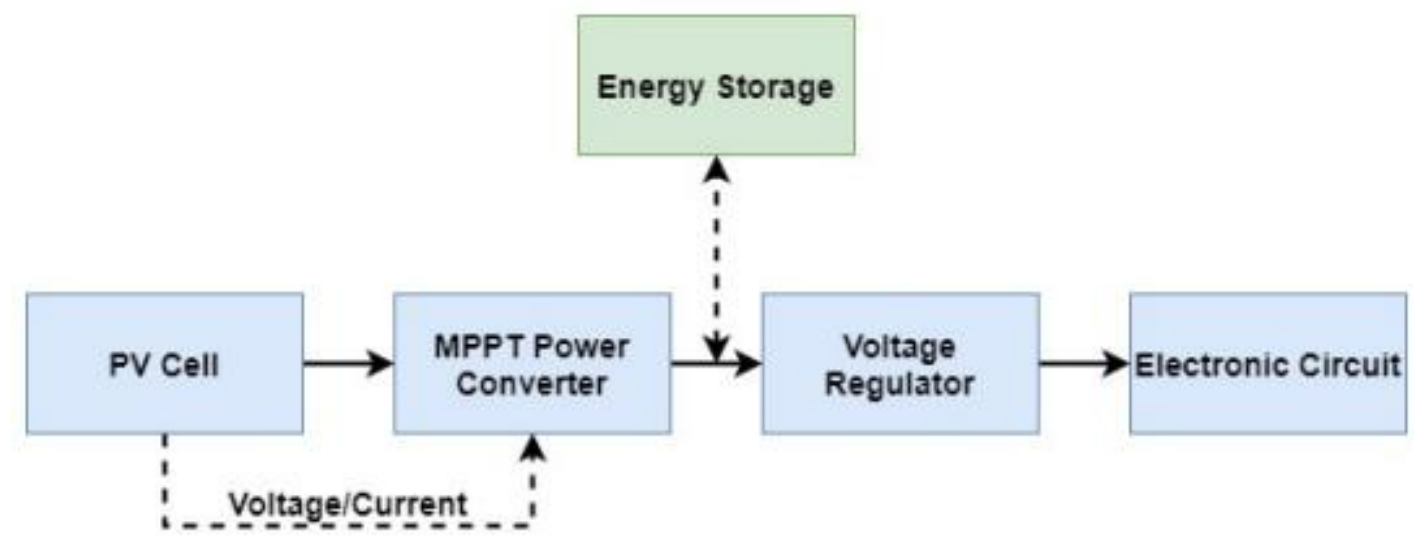

Figure 2. Harvest-Use Energy Harvesting Architecture

The harvest-use architecture do not utilize voltage converters and it avoids the storing energy storage in the long duration; hence, disadvantage of the earlier harvest demonstrated the energy saving method. When they harvest energy from the neighboring energy, the storage materialslike the supercapacitors as well as batteries that can be rechargedhas to be chosenbased on the environmental situations. In few gadgetswhen the primary storage exhaust, the secondary storage could be utilized. One of that type is the solar energy harvester. It is made of voltage regulator, maximum power point tracking (MPPT) converter, and photovoltaic cell. One voltage regulator is applied to charge the batteries while another is utilized for constant power provision for the IoT devices. 
directly to power the IoT equipment as as an as a model conserve energy. depicted in Figure 4, while a PV cell is taken

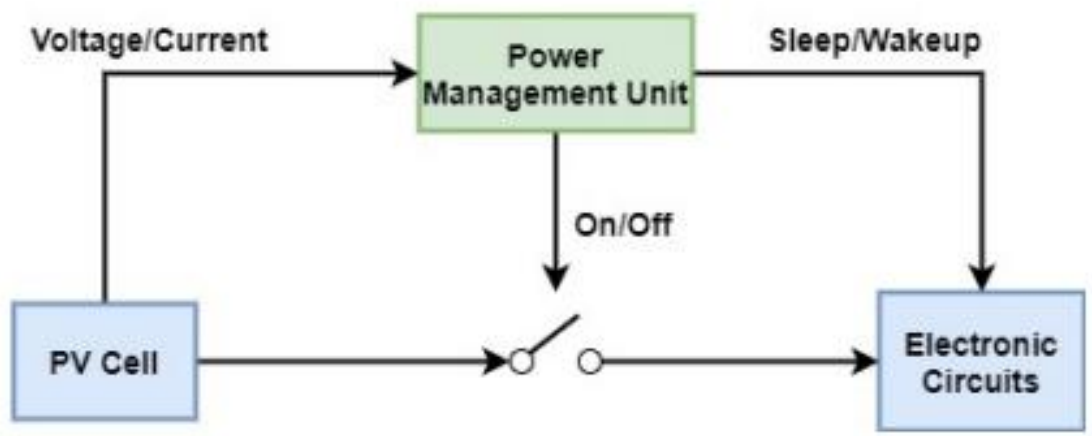

Figure 3. Harvest-Store-Use Energy Harvesting Architecture

For the medicine sectorthat have the triple issues [20], the effect of this sector on environmentis a global concern. This gave rise to regulators' focus has been brought into it [21]. The energy consumption of this sector (whose largest sub-segment is 'hospitals') has been increasing because of various factors [22,23]. This is developed to become a right placeto employ of 'Green IT'. Green takes energy efficiency also into consideration; from that perspective functional area-wise energy consumptions as well as carbon emissions of a hospitals are depicted in Table 1.

\begin{tabular}{|l|l|l|}
\hline $\begin{array}{l}\text { Functional } \\
\text { Area of Use }\end{array}$ & $\begin{array}{l}\text { Energy } \\
\text { Consumptio } \\
\mathbf{n}\end{array}$ & $\begin{array}{l}\text { Carbon } \\
\text { Emission }\end{array}$ \\
\hline Ward & 1,350 & 293 \\
\hline
\end{tabular}

\begin{tabular}{|l|l|l|}
\hline Surgery areas & 844 & 268 \\
\hline Back area & 619 & 176 \\
\hline $\begin{array}{l}\text { Consulting } \\
\text { areas } \\
\text { (consulting } \\
\text { rooms etc.) }\end{array}$ & 510 & 166 \\
\hline $\begin{array}{l}\text { Administrati } \\
\text { on \& Office } \\
\text { blocks }\end{array}$ & 474 & 154 \\
\hline $\begin{array}{l}\text { Corridors } \\
\text { (24hrs) }\end{array}$ & 349 & 95 \\
\hline
\end{tabular}

Table 1. Carbon emissions in hospital sectors

\section{Green IoT (G-IoT) in educational institutions:}

The curriculum for engineering mainly revolves around content and design. Students attend the lectures and perform laboratory experiments in the universities [24]. Hence, the online teaching method's 
advent also brings about certain drawbacks, such as laboratories' unavailability and equation manipulation [25]. Although there is standard delivery of course content, which is essential information, the content must be given more significance. As there have been developments in IoT, it has enabled a virtual space for object representation, which may lack quality but still stands better than the conventional teaching methods. By adopting such methods, a wide range of various engineering disciplines will be available and accessible to all [27].

In an educational setting, the G- IoT secures ITC resources' sustainability and encourages the users, such as the faculty members and the staff, to have a greener behavior [28]. Concerning economic, social, and environmental sustainability in education with G- IoT, the following tasks must be essentially performed [28,29]. . Optimal utilization of resources: This process can be carried by various methods such as shutting down personal computers and laboratory equipments when not in use and enabling them with standby or sleep mode, power saving methods like reducing the screen brightness and using cloud computing, enabling devices with multifunctional types of equipment like printer, copier, scanner, - 273 - fax and encouraging e- communication like teleconferencing with online collaboration tools. The use of smart grids and lost cost sensors will bring about a more finely tuned HVAC system. - Dispose, reuse and recycle ICT equipment - This can be done by reassigning old IT devices, repairing ICT devices rather than replacing it, and following eco-friendly methods for recycling ICT devices. · Increase awareness regarding G- IoT the faculty members, students and administrative members. Practicing IOT procedures has the benefits of saving natural resources and cost reduction.

\section{Tech-enabled classrooms with green communication technologies}

In today's date green technology and sustainability are the most concerned areas of interest. Sudden and frequent climatic changes over the past recent years indicate the need for public attention towards Earth's stability. Although ITC provides several advantages, it does not benefit the environment as it consumes large quantity of electricity and produces carbon dioxide [30]. According to the studies related to the impacts of ITC on the environment, ITC is proved to cause a threat and offer a solution at the same time. It is essential to understand 
that ICT can greatly contribute to developing sustainability [31]. At present the principal issue is Global Warming caused due to excessive emission of carbon [32]. As green computing is undergoing advancements brings a hope of healthier environment. Green or Eco sustainability is the ability of one or more substances to sustain and function for a long time.

The presence and rise of various collectivities of elements are accepted at recognized levels and in known frameworks [33]. Green technology is an effort made to update the government regarding sustainability and a platform that allows the government officials to communicate with the organizations that undertake the task of developing and distributing green technologies [34]. As for now no adverse effects of using Green ICT practices have been observed or reported. It is presently high time for academicians to begin sparing fuel sources and energy for future eras apart from saving money and assets for them [35]. Utilizing ICT in educational settings has resulted in excessive emission of carbon dioxide, high usage of energy and production of hazardous waste [36]. Production of high amount of e- waste is very common in educational institutions and hence is advised to use Green ICT.
Additionally, this is also a cost-effective method as it minimizes the computational facility waste [37]. Applying Green ICT in educational institutions has proven to attain cost effective results and corporate social obligation [38]. Green ICT has been an interesting research area focusing on productive utilization of IT equipment. These all efforts together contribute to lessening greenhouse gas emanations.

\section{Green IoT in Industry 4.0}

A dependable method to reduce energy consumption [39] which is essential for production [40], is obtained by combining the management algorithms and Industry 4.0 technologies [41,42]. The performance of the production procedure [43] is assessed by examining the most preferred indicator used for manufacturing performance [44]. Overall equipment effectiveness (OEE) is the principal measure in the mass production environment and commonly used to measure production equipment efficiency [45]. Industry 4.0 technologies can also improve the manufacturing process and decrease energy consumption [46, 47]. The decision-makers must assess the improvements in energy use and the manufacturing costs [48, 49]. Digitizing the manufacturing process stands 
up to be the main features of Industry 4.0. This will be efficient for saving energy, by optimizing or replacing specific technologies and applying software that provides energy optimization functionality or adapts to the business processes [50]. According to this concept, Industry 4.0 appears to be the potential to provide a more streamlined information flow [51]. Nevertheless, a combination of these two methods: sustainable energy and Industry 4.0 is a novel approach, hence, there are several opportunities to add the concept of sustainable energy to digital factory.

\section{Controlling energy consumption and} carbon emissions in industrial sectors by green cloud models

The emission of carbon from the devices creates the risks in business domain. In order to decrease the risk of carbon emission, standard measurement metrics are integrated into the IT-business relationship. The year 2008 witnessed a $1.7 \%$ increase in carbon emissions, $70 \%$ greater than the average increase in the year 2010. Additionally, mobile phones and data centers account for the major contribution of carbon. Electrical servers like UPS and HVAC units that operate continuously require a large amount of electricity. Google data center operates at $35^{\circ} \mathrm{C}\left(95^{\circ} \mathrm{F}\right)$ with natural air cooling. According to an announcement made by Google in 2016, by 2017, all of its data centers and offices would be would be using renewable energy and in places where renewable energy is not accessible, utility grids from coal and natural gas will be used. Production of electricity is the second cause of greenhouse gas (GHG), accounting to about $28.4 \%$. The two essential aspects of producing green IT are improving efficiency and finding the renewable source of energy. Renewable energy can be obtained from the environment.

Research studies in the future will mainly focus on energy efficiency that can be obtained by decreasing carbon emission and computational cost naturally. However, the main problem is to cool the warehousesized data center. The servers in the data centers are the major energy-hogging element which uses50\% to $90 \%$ of electricity. The three servers in data centers are volume servers, mid-range servers, and high-end servers [52].

Cloud computing has developed to be a technology to compute infrastructure, platforms, and software remotely accessed through the internet. Cloud computing leads to energy efficiency by eliminating 
redundancies, improving the utilization of resources, independent of location, adjusting the resource utilization related to the current availability of the resources, and the efficient utilization by the cloud provider. Table 2 illustrates the comparison of carbon emission among various countries. Green Cloud Computing is used for well-organized processing, application of computing infrastructure and turn down the energy consumption. The success of cloud computing depends on the development of green cloud. The green cloud aims to reduce energy consumption and decrease the utilization of hazardous materials in data centers.

\begin{tabular}{|c|c|c|c|c|}
\hline $\begin{array}{l}\mathrm{CO} 2 \\
\text { emission } \\
\text { / year }\end{array}$ & $\begin{array}{l}\text { Server } \\
\mathrm{s}\end{array}$ & $\begin{array}{l}\text { Storag } \\
\mathrm{e}\end{array}$ & $\begin{array}{l}\text { Networ } \\
\mathrm{k}\end{array}$ & $\begin{array}{l}\text { Data } \\
\text { cente } \\
\mathrm{r}\end{array}$ \\
\hline E.U. & 727 & 145 & 97 & 1745 \\
\hline $\begin{array}{l}\text { United } \\
\text { Kingdom }\end{array}$ & 911 & 182 & 121 & 2186 \\
\hline France & 126 & 25 & 17 & 302 \\
\hline Germany & 985 & 197 & 131 & 2365 \\
\hline $\begin{array}{l}\text { Russian } \\
\text { Federatio } \\
\text { n }\end{array}$ & 903 & 181 & 120 & 2166 \\
\hline U.S.A. & 1039 & 208 & 139 & \\
\hline
\end{tabular}

\begin{tabular}{|l|l|l|l|l|}
\hline & & & & 2494 \\
\hline Canada & 345 & 69 & 46 & 828 \\
\hline Australia & 1700 & 340 & 227 & 4080 \\
\hline Singapor & 1033 & 207 & 138 & \\
\hline Japan & 1027 & 205 & 137 & 2479 \\
\hline Korea & 1126 & 225 & 150 & 2464 \\
\hline India & 1768 & 354 & 236 & 2702 \\
\hline China & 1578 & 316 & 210 & \\
\hline
\end{tabular}

Table 2. Carbon emissions in various countries

\section{Conclusion}

Recent decades have witnessed embodiments of connectivity forms that interlinks the stakeholders across the healthcare ecosystem to process the data. This assists to glean actionable insights to accomplish customer experience, care delivery, and operational excellence. This survey envisioned some of the technologies for performing energy saving operations in reducing the carbon emissions and harmful gases. Furthermore, the importance of the green IoT is widened in this research.

\section{References:}


[1] L. Catarinucci, D. Danno, L.Mainetti, L.Palano, L.Patrono,M.Stefanizzi, and L.Tarricone, "An IoT-Aware Architecture for Smart Healthcare Systems", Internet of Things Journal, IEEE, Dec. 2015, vol. 2,pp. 515-526.

[2] M. Rou and S. Paca, "A WBAN-ECG approach for real-time long-term monitoring", 2013 8TH International symposium on advanced topics in electrical engineering (ATEE), Bucharest, 2013,pp. 1-6.

[3] L.Yan, L.Zhong and N.K.Jha, "Energy comparison and optimization of wireless body-area network technologies", Proceedings of the ICST 2nd international conference on Body area networks, ICST, Italy,2007,pp. 1-8.

[4] M.Magno, T.Polonelli, F.Casamassima, A.Gomez, E. Farella and M.Benini, "Energy-efficient context aware power management with asynchronous protocol for body sensor network", Mobile Networks and Applications 22, no. 5 (2017): 814-824.

[5] P. Kolios, C. Panayiotou, G. Ellinas, and M. Polycarpou, "Data-Driven Event Triggering for IoT Applications", IEEE Internet of Things Journal, vol. 3, no. 6, pp. 1146-1158, Dec. 2016.
[6] O. Omeni, A. C. W. Wong, A. J. Burdett, and C. Toumazou, "Energy Efficient Medium Access Protocol for Wireless Medical Body Area Sensor Networks", IEEE Transactions on Biomedical Circuits and Systems, vol. 2, no. 4, pp. 251-259, Dec. 2008.

[7] A.A.Babayo, M.H. Anisi, and I.Ali, "A Review on energy management schemes in energy harvesting wireless sensor networks", Renewable and Sustainable Energy Reviews,11761184, Sep. 2017

[8] D.C. Hoang, Y.K. Tan,H.B. Chng, and S.K. Panda, "Thermal Energy Harvesting From Human Warmth For Wireless Body Area Network In Medical Healthcare System”, 2009 International Conference on Power Electronics and Drive Systems (PEDS), Taipei, 2009, pp. 1277-1282.

[9] S.Pathak, M.Kumar, A.Mohan, and B. Kumar, "Energy optimization of zigbee based wban for patient monitoring", Procedia Computer Science, 2015,70,414-420.

[10] A.Silva, M. Liu, and M.Moghaddam, "Power-Management Techniques forWireless Sensor Networks and Similar Low-Power Communication Devices Based on Nonrechargeable 
Batteries", IEEE Communications Magazine 55, no. 1 (2017): 84-91.

[11] A. M. Nia, M. Mozaffari-Kermani, S. Sur-Kolay, A. Raghunathan, and N. K. Jha, "Energy-efficient long-term continuous personal health monitoring," IEEE Trans. Multi-Scale Comput. Syst., vol. 1, no. 2, pp. 85-98, Apr./Jun. 2015.

[12] N. K. Mangali and V. K. Kota, "Health monitoring systems: An energy efficient data collection technique in wireless sensor networks," in Proc. Int. Conf. Microw., Opt. Commun. Eng. (ICMOCE), Dec. 2015, pp. 130-133.

[13] J. Granados, A.-M. Rahmani, P. Nikander, P. Liljeberg, and $\mathrm{H}$. Tenhunen, "Towards energy-efficient HealthCare: An Internet-of-Things architecture using intelligent gateways," in Proc. 4th Int. Conf. Wireless Mobile Commun. Healthcare, Nov. 2014, pp. 279-282.

[14] T. N. Gia, N. K. Thanigaivelan, A.-M. Rahmani, T. Westerlund, P. Liljeberg, and H. Tenhunen, "Customizing 6LoWPAN networks towards Internetof-Things based ubiquitous healthcare systems," in Proc. 32nd NORCHIP Conf., Nordic Microelectron. Event (NORCHIP), Oct. 2015, pp. 1-6.
[15] T. Rault, A. Bouabdallah, Y. Challal, and F. Marin, "Energy-efficient architecture for wearable sensor networks," in Proc. IFIP Wireless Days (WD), Nov. 2014, pp. 1-8.

[16] ] A. Papageorgiou, M. Zahn, and E. Kovacs, "Efficient auto-configuration of energy-related parameters in cloudbased IoT platforms," in Proc. IEEE 3rd Int. Conf. Cloud Netw. (CloudNet), Oct. 2014, pp. 236-241.

[17] W. Li et al., "System modelling and performance evaluation of a threetier Cloud of Things," Future Gener. Comput. Syst., vol. 70, pp. 104-125, May 2017.

[18] H. Dubey, J. Yang, N. Constant, A. M. Amiri, Q. Yang, and K. Mankodiya, "Fog data: Enhancing telehealth big data through fog computing," Proc. ASE Big Data Social Inform., 2015, pp. 14:1-14:6.

[19] Yuan, F.; Zhang, Q.; Jin, S.; Zhu, H. Optimal harvest-use-store strategy for energy harvesting wireless systems. IEEE Trans. Wirel. Commun. 2014, 14, 698-710. [CrossRef]

[20] N. Godbole, J. Lamb "The Triple Challenge for the Healthcare Industry: Sustainability, Privacy, and Cloud- 
Centric Regulatory Compliance", CEWIT 2013 paper.

[21] Profile of the Healthcare Industry, EPA Office of Compliance Sector Notebook Project February 2005.

[22] N. Godbole, J. Lamb "Calculating a Hospital's IT Energy Efficiency and Determining Cost Effective Ways for Improvement, CEWIT 2014 paper.

[23] Field R. I. Health Care Regulation in America: Complexity, Confrontation and Compromise. New York: Oxford University Press; 2007.

[24] V. Vujovic and M. Maksimovic, "The Impact of the Internet of Things on Engineering Education," The Second International Conference on Open and Flexible Education (ICOFE), Hong Kong, 2015, pp. 135-144

[25] N. Cavus and D. Ibrahim, "Is Blended Learning the Solution to WebBased Distant Engineering Education?," 7th International Educational Technology (IETC) Conference, Nicosia, Cyprus, 2007.

[26] K. Craig, „Innovating the Engineering Education Model,“ 2016, [Online]: http://machinedesign.com/contributingtechnicalexperts/innovatingengineering-education-mode
[27] J. Bourne, D. Harris and F. Mayadas, "Online engineering education: Learning anywhere, anytime," Sloan-C Publications, Journal of Asychronous Learning Networks, 9(1), 2004.

[28] K. Suryawanshi and S. Narkhede, "Green ICT at Higher Education Institution: Solution for Sustenance of ICT in Future," International Journal of Computer Applications (0975 - 8887), Vol. 107 - No 14, 2014. pp. 35-38.

[29] NCB, "Green ICT guidelines for businesses," National Computer Board [Online]:

http://www.ncb.mu/English/Documents /Downloads/Reports\%20and\%20Guidel ines/Green\%20ICT\%20Guidelines\%20f or\%20Businesses.pdf

[30] Managing the company's carbon footprint the emerging role of ICT, A report from Economist IntelligencyUnit,Feb 2008, Online Available at www.graphics.eiu.com , [ Accessed 30 Nov 2013]

[31] ZacharoulaAndreopoulou,E. Stiakakis and MaroViachopoulou, "Green ICT Applications towards the Achievement of Sustainable Development", Chapter from Book Title : E-Innovation for Sustainable Development of Rural 
Resources During Global Economic

Crisis , IGI Global,2014,pp 11-21.

[32] J.Porritt, “Green IT a Global

Benchmark: a Report on Sustainable IT in the USA,UK,Australia and India”,Fujitsu,Australia,2010.

[33] Molla A., Vanessa C. Brain Corbitt , Hepu Deng, Say Yen Teoh, "EReadiness to G-Readiness Developing a Green Information Technology Readiness Framework", 19th Australian Conference on Information Systems , 35 Dec 2008 , Christchuch, Australia , pp 669-678.

[34] Kallmorgen, J.-F. ,'Towards a Global Green Recovery Supporting Green Technology Markets", Atlantic Task Force Global Green Recovery, 2009.

[35] Suryawanshi K.,Narkhde S. ,"Evolution Of Green ICT Implementation At Education Institutions Study With Reference To Maharashtra”, International Journal of Advanced Research in Engineering and Technology,ISSN 0976 -6480(Print), ISSN 0976 - 6499(Online) Volume 4, Issue 6, September - October ,2013, pp 216-221.

[36] Supaporn Chai-Arayalert, Keiichi Nakata,'The Evolution of Green ICT Practice: UK Higher Education

Institutions Case Study", IEEE International Conference on Green Computing and Communications, 2011, United Kingdom, pp 220-225.

[37] Suryawanshi K.,Narkhde S. ,"Evolution of Green ICT Implementation In Education Sector: A Study of Developed and Developing Country", International Journal of Management ,ISSN 0976 -6502(Print) ISSN 0976 6510(Online) Volume 4, Issue 2, March - April 2013, pp 91-98.

[38] Suryawanshi K.,Narkhde S. ,'Green ICT Implementation at Professional Education Institutions: A Study from Indian Context “, International Journal of Advanced Research in Computer Science and Electronics Engineering IJARCSEE ,Volume 1, Issue 8, Oct 2012, ISSN: 2277 - 9043, pp 111-114.

[39] Mohamed, N.; Al-Jaroodi, J.; LazarovaMolnar, S. Leveraging the Capabilities of Industry 4.0 for Improving Energy Efficiency in Smart Factories. IEEE Access 2019, 7, 18008-18020. [CrossRef]

[40] Shrouf, F.; Ordieres-Meré, J.; Miragliotta, G. Smart factories in Industry 4.0: A review of the concept and of energy management approached in production based on the Internet of 
Things paradigm. In Proceedings of the 2014 IEEE International Conference on Industrial Engineering and Engineering Management, Selangor, Malaysia, 9-12 December 2014; pp. 697-701. [CrossRef]

[41] Adolph, S.; Kübler, P.; Metternich, J.; Abele, E. Overall Commissioning Effectiveness: Systematic Identification of Value-added Shares in Material Supply. Procedia CIRP 2016, 41, 562567. [CrossRef]

[42] The Federal Ministry of Education and Research. Energy Efficiency in Production: Future Action Fields; Fraunhofer Gesellschaft: Munich, Germany, 2008.

[43] Nakajima, S. Introduction to TPM: Total Productive Maintenance; Productivity Press Inc.: New York, NY, USA, 1988.

[44] SEMI. Semi E79-0200 Standard for Definition and Measurement of Equipment Productivity. Semicond. Equip. Mater. Int. 1999, 1-24.

[45] de Ron, J.; Rooda, J.E. OEE and equipment effectiveness $\mathrm{E}$ : An evaluation. Int. J. Prod. Res. 2009, 12, 1537-1546.

[46] May, G.; Taisch, M.; Prabhu, V.V.; Barletta, I. Integrity and Internal
Control in Information Systems; Energy related key performance indicatorsState of the art, gaps and industrial needs; Springer: Berlin/Heidelberg, Germany, 2013; Volume 414, pp. 257267. [CrossRef]

[47] Wang, W.; Yang, H.; Zhang, Y.; Xu, J. IoT-enabled real-time energy efficiency optimisation method for energyintensive manufacturing enterprises. Int. J. Comput. Integr. Manuf. 2017, 31, 362-379. [CrossRef]

[48] Zhang, Y.; Ma, S.; Yang, H.; Lv, J.; Liu, Y. A big data driven analytical framework for energy-intensive manufacturing industries. J. Clean. Prod. 2018, 197, 57-72. [CrossRef]

[49] Kang, H.S.; Lee, J.Y.; Choi, S.; Kim, H.; Park, J.H.; Son, J.Y.; Kim, B.H.; Noh, S.D. Smart manufacturing: Past research, present findings, and future directions. Int. J. Precis. Eng. Manuf. Green Technol. 2016, 3, 111-128. [CrossRef]

[50] UNIDO. Accelerating Clean Energy Through Industry 4.0 Manufacturing the Next Revolution; United Nations Industrial Development Organization: Vienna, Austria, 2017; p. 54.

[51] Zina Chkirbene, Ala Gouissem, Rachid Hadjidj, SebtiFoufou, RidhaHamila 
"Efficient techniques for energy saving in data center networks", Volume 129, Pages 111-124, Computer Communication-Elsevier 2018.
[52] Moeuf, A.; Pellerin, R.; Lamouri, S.; Tamayo, S.; Barbaray, R. The industrial management of SMEs in the era of Industry 4.0. Int. J. Prod. Res. 2017, 56, 1118-1136. [CrossRef] 